\title{
Stability-Indicating Spectrofluorimetric and RP-HPLC Methods for the Determination of Aspirin and Dipyridamole in their Combination
}

\author{
Hassan H. Hammud ${ }^{*}$,, Fawzy A. El Yazbi ${ }^{\mathrm{b}}$, Mohamad E. Mahrous ${ }^{\mathrm{c}}$, Ghassan M. Sonji ${ }^{\mathrm{b}}$ and Nada \\ M. Sonji \\ ${ }^{a}$ Chemistry Department, Faculty of Science, Beirut Arab University, Lebanon \\ ${ }^{b}$ Pharmaceutical Analytical Chemistry Department, Faculty of Pharmacy, Beirut Arab University, Lebanon \\ ${ }^{c}$ Medicinal Chemistry Department, Faculty of Pharmacy, Beirut Arab University, Lebanon
}

\begin{abstract}
Spectrofluorimetric and high performance liquid chromatographic methods have been developed for the accurate and sensitive determination of Aspirin in mixture with Dipyridamole and in presence of its degradation product (Salicylic acid). The spectrofluorimetric method was based on the use of the first and second derivatives of the ratio of the emission spectra with a zero-crossing technique. The ratio spectra were obtained by dividing the emission spectrum of the ternary mixture by that of one of the components. The other components were quantified from their respective calibration graphs treated similarly. The proposed RP-HPLC method utilized an Adsorbosil $\mathrm{C}_{8}, 10 \mu \mathrm{m}, 250 \mathrm{mmx} 4.6 \mathrm{~mm}$ i.d. column, at ambient temperature, optimum mobile phase consisted of water-acetonitrile-ortho-phosphoric acid $(65: 35: 2 \mathrm{v} / \mathrm{v} / \mathrm{v})$, with flow rate monitored at $1.5 \mathrm{ml} / \mathrm{min}$, and UV detection at $250 \mathrm{~nm}$. The total chromatographic time per sample was about 6 min with dipyridamole, aspirin and salicylic acid eluting at retention times 2.2, 3.8 and 4.6 min, respectively. Evaluation of linearity, accuracy, precision, selectivity and sensitivity of the methods produced satisfactory results.

The objective of this work was to introduce new analytical methods for this ternary mixture, as the literature reveals only one method of analysis. The proposed methods were able to quantify Aspirin, Dipyridamole and Salicylic acid, irrespective of the percentage of the latter in sample; and have been successfully applied to the commercial pharmaceutical formulations without any interference of excipients.
\end{abstract}

Keywords: Dipyridamole, aspirin, salicylic acid, spectrofluorimetry, stability-indicating, derivative ratio, RP-HPLC.

\section{INTRODUCTION}

The combination of Aspirin and Dipyridamole is widely used to reduce thrombosis in patients with thrombotic diseases. This antithrombotic action results from additive antiplatelet effects of both drugs. Aspirin $(A S P)$ inhibits platelet aggregation by irreversible inhibition of platelet cyclooxygenase and thus inhibiting the generation of Thromboxane A2. Dipyridamole $(D I P)$ inhibits the uptake of adenosine into platelets and endothelial cells, thus decreasing the adhesion of platelets to thrombogenic surfaces [1].

Stability testing forms an important part of the process of drug product development. The purpose of stability testing is to provide evidence on how the quality of a drug substance or drug product varies with time under the influence of a variety of environmental factors such as temperature, humidity and light, and enables recommendation of storage conditions, retest periods and shelf lives to be established. The two main aspects of drug product that play an important role in shelf life determination are assay of active drug and degradation products generated, during the stability study. The assay

*Address correspondence to this author at the Chemistry Department, Faculty of Science, Beirut Arab University, Lebanon; Tel: +961-1-300110, Ext. 2477; Fax: +961-1-300110, Ext. 2599; Email: hhammud@yahoo.com of drug product in stability test sample needs to be determined using a stability-indicating method, as recommended by the International Conference on Harmonization (ICH) guidelines [2]. The objective of this work was to develop simple, precise and rapid analytical methods, which would serve as stability-indicating assay procedures for combination of $A S P$ and $D I P$.

Literature showed a spectrofluorimetric method for simultaneous determination of $A S P$ and DIP [3], but this method lack stability-indicating nature. Only one stabilityindicating spectrophotometric method has been reported for $A S P, D I P$ and $S A L$ determination [4].

Direct spectrofluorimetric method is not suitable for simultaneous determination of this ternary mixture due to spectral overlapping. Derivative spectrophotometry is an analytical technique of great utility to overcome the interference of some drugs at the zero-crossing points $[5,6]$. However, sometimes the derivative technique cannot cope with the level of interference especially when the spectra are strongly overlapped or in case of ternary mixtures.

Derivative of ratio spectra has been developed by Salinas [7] to resolve mixtures of chromophores with overlapped spectra by measuring the amplitude of the first derivative of the ratio spectra obtained by using the selected divisor. This method has been extended to determine binary or ternary mixtures spectrophotometrically and spectrofluorimetrically 
by the use of Salinas method and zero-crossing technique [810]. Therefore, derivative ratio of emission spectra with zero-crossing technique was utilized to solve spectral overlapping of this ternary mixture.

To discuss the theoretical background of this method, consider a mixture of three compounds, $\mathrm{M}, \mathrm{N}$ and $\mathrm{P}$. If Beer's law is obeyed for all the compounds over the whole wavelength range used and the path-length is $1 \mathrm{~cm}$, the emission spectrum of the mixture is defined by the equation:

$I_{m, \lambda i}=K \in_{M, \lambda i} C_{M}+K^{\prime} \in_{N, \lambda i} C_{N}+K^{\prime \prime} \in_{P, \lambda i} C_{P}$

where $I_{m, \lambda i}$ is the fluorescence intensity of the mixture at wavelength $\lambda_{i} ; K, K^{\prime}$ and $K^{\prime \prime}$ are constants depending on intensity of incident light beam, quantum efficiency of fluorescence and pathlength; $\in_{M, \lambda i}, \in_{N, \lambda i}$ and $\in_{P, \lambda i}$, are the molar absorptivities of $\mathrm{M}, \mathrm{N}$ and $\mathrm{P}$, at wavelength $\lambda_{i}$; and $C_{M}, C_{N}$ and $C_{P}$ are the molar concentrations of $\mathrm{M}, \mathrm{N}$ and $\mathrm{P}$, respectively.

If Eq. (A.1) is divided by the corresponding equation for the emission spectrum of a standard solution of one of the components (e.g., $\mathrm{M}$ of concentration $C_{M}^{o}$ ) and the first derivative of the result is obtained, the following equation can be written:

$$
\begin{aligned}
& d / d \lambda\left[I_{m, \lambda i}\right] / \in_{M, \lambda i} C_{M}^{o}=C_{N} / C_{M}^{o} d / d \lambda\left[\epsilon_{N, \lambda i}\right] / \in_{M, \lambda i} \\
& +C_{P} / C_{M}^{o} d / d \lambda\left[\in_{P, \lambda i}\right] / \epsilon_{M, \lambda i}
\end{aligned}
$$

This equation indicates that the derivative ratio spectrum of the ternary mixture is independent on the value of $C_{M}$, and dependent on the value of $C_{N}, C_{P}$ and $C_{M}^{o}$ in the ternary mixtures.

The content of $\mathrm{N}$ and $\mathrm{P}$ can be resolved by the zerocrossing method by measuring at adequate wavelengths and by use of calibration graphs.

Two calibration graphs are obtained by recording and storing the emission spectra of solution of pure $\mathrm{N}$ and pure $\mathrm{P}$ at different concentrations and the emission spectrum of a solution of pure $\mathrm{M}$ of concentration $C_{M}^{o}$. The amplitudes of the emission spectra of $\mathrm{N}$ and $\mathrm{P}$ are then divided, wavelength by wavelength, by the corresponding amplitudes for $\mathrm{M}^{\mathrm{o}}$. The "ratio spectra" thus obtained are then differentiated with respect to wavelength.

The derivative values:

$$
C_{N} / C_{M}^{o} d / d \lambda\left[\epsilon_{N, \lambda i}\right] / \epsilon_{M, \lambda i}
$$

are plotted against $C_{N}$ for a given wavelength corresponding to zero-crossing of the ratio of spectrum of $\mathrm{P}$ (at this wavelength):

$$
d / d \lambda\left[\epsilon_{P, \lambda i}\right] / \in_{M, \lambda i} C_{M}^{o}=0
$$

to give a calibration graph. The calibration graph for $\mathrm{P}$ is obtained by plotting derivative values:

$$
C_{P} / C_{M}^{o} d / d \lambda\left[\epsilon_{P, \lambda i}\right] / \epsilon_{M, \lambda i}
$$

against $C_{P}$ at $\lambda_{i}$ corresponding to zero-crossing of the ratio of the spectrum of $\mathrm{N}$ (at this wavelength):

$d / d \lambda\left[\epsilon_{N, \lambda i} C_{N}\right] / \epsilon_{M, \lambda i} C_{M}^{o}=0$

Application of the method to the sample containing M, N and $\mathrm{P}$ and use of the calibration graphs, will then give the values of $C_{N}$ and $C_{P}$ in the ternary mixtures.

$\mathrm{M}$ can be determined by an analogous procedure. If we use the emission spectrum of standard solution of $\mathrm{N}$ or $\mathrm{P}$ of concentration $C_{N}^{o}$ or $C_{P}^{o}$, we can determine $\mathrm{M}$ and $\mathrm{P}$ in the presence of $\mathrm{N}$, or $\mathrm{M}$ and $\mathrm{N}$ in the presence of $\mathrm{P}$.

The major problem encountered during the analysis of this combination $(A S P, D I P$ and $S A L)$ was attributed to the strong spectral overlapping of these drugs in mixture. This spectral interference would further complicate such analysis, especially if one of the components is weakly absorbing or exists as a minor relative to the other as in the case of $S A L$. It was found that the use of derivative ratio of emission spectra with zero-crossing technique can solve this problem.

High pressure liquid chromatography (HPLC) was also used for the resolution of complex mixtures with overlapping spectra [11]. The proposed HPLC method was able to separate both drugs from the degradation product.

This paper describes new, simple, rapid, reliable and sensitive stability-indicating spectrofluorimetric and isocratic reversed-phase HPLC methods for simultaneous determination of $A S P$ and $D I P$ in presence of the closely related $A S P$ deacetylated degradation product $(S A L)$, which has a particular importance because of its identification as an impurity in $A S P$ powder. The linearity of response, accuracy and precision of the described methods have been checked.

\section{MATERIALS AND METHODOLOGY}

\subsection{Apparatus}

Fluorescence spectra and measurements were taken on a JASCO spectrofluorimeter model FP-6200 using $1 \mathrm{~cm}$ quartz cells.

For the derivative ratio method, the emission spectra were recorded on the same spectrofluorimeter and supported with Jasco Spectra Manager software for GULLIVER Ver. 1.53 .

HPLC analysis was performed with a Jasco chromatograph (Japan), equipped with an isocratic PU-1580 pump, MD-1510 UV/Vis detector and $20 \mu \mathrm{L}$ loop injector. Compounds were separated on an Adsorbosil $\mathrm{C}_{8}$ analytical column $(250 \mathrm{~mm}$ x $4.6 \mathrm{~mm}$, particle size $10 \mu \mathrm{m})$. Mobile phase and the solutions were degassed and vacuum filtered through $0.2 \mu \mathrm{m}$ membrane filter before use.

The mobile phase consisted of water-acetonitrile-orthophosphoric acid $(65: 35: 2 \mathrm{v} / \mathrm{v} / \mathrm{v})$. Isocratic elution was performed at a flow rate of $1.5 \mathrm{ml} / \mathrm{min}$. Before each injection, the column was equilibrated to stable baseline at a flow rate of $1.5 \mathrm{ml} / \mathrm{min}$ and at ambient temperature. 


\subsection{Materials and Reagents}

All chemicals used were of analytical grade. $D I P$ was kindly supplied by CID Co., Egypt; $A S P \& S A L$ were provided by Fluka Chemie GmbH, Switzerland; PersantinPlus ${ }^{\circledR}$ capsules, containing $75 \mathrm{mg} D I P$ and $50 \mathrm{mg}$ ASP per capsule was kindly supplied by CID Co., Egypt.

\subsection{Standard Solutions}

\subsubsection{Spectrofluorimetric Method}

Standard stock solutions of $A S P, D I P$ and $S A L$ were prepared by dissolving $50 \mathrm{mg}, 75 \mathrm{mg}$ and $20 \mathrm{mg}$ of each drug in $100 \mathrm{ml} 1 \% \mathrm{v} / \mathrm{v}$ glacial acetic acid in chloroform, respectively. The stock solutions were subsequently diluted with the same solvent to achieve a final solution of $40 \mu \mathrm{g} / \mathrm{ml} A S P, 60$ $\mu \mathrm{g} / \mathrm{ml} D I P$, and $16 \mu \mathrm{g} / \mathrm{ml} S A L$.

\subsubsection{HPLC Method}

Standard stock solutions of $A S P, D I P$ and $S A L$ were prepared by dissolving $50 \mathrm{mg}, 75 \mathrm{mg}$ and $20 \mathrm{mg}$ of each drug in $100 \mathrm{ml}$ methanol, respectively.

\subsection{Calibration Graphs}

\subsubsection{Spectrofluorimetric Method}

Various aliquots from each working standard solution, within the concentration range stated in Table 1, were transferred into a set of $25 \mathrm{ml}$ volumetric flasks, and the solutions were completed to mark with $1 \% \mathrm{v} / \mathrm{v}$ glacial acetic acid in chloroform.

The emission spectra of the standard solutions were recorded within the wavelength range $220-700 \mathrm{~nm}$ and stored, using $270 \mathrm{~nm}$ as the excitation wavelength.

\subsubsection{HPLC Method}

Serial dilutions from the standard stock solutions were made to obtain the concentration range stated in Table 2 . Measurements were made with injection volume $20 \mu 1$ and UV detection at $250 \mathrm{~nm}$, as both components showed reasonable response at this wavelength.

\subsection{Sample Preparation}

A weighed amount of the mixed contents of ten capsules, equivalent to $75 \mathrm{mg} D I P$ was transferred into $100 \mathrm{ml}$ volumetric flask and dissolved in $1 \% \mathrm{v} / \mathrm{v}$ glacial acetic acid in chloroform for spectrofluorimetric method, and in methanol for HPLC method then completed to the mark with the same solvents and filtered. The solutions were then diluted to a concentration range stated in Tables $\mathbf{1}$ and $\mathbf{2}$. The procedures were completed as under calibration graphs.

\section{RESULTS AND DISCUSSION}

$D I P$ and $A S P$ are formulated in this binary mixture with the ratio of $75: 50$.

Table 1. Assay Parameters and Effect of Divisor Concentration on Determination of $A S P, D I P$ and $S A L$ by the Spectrofluorimetric Method

\begin{tabular}{|c|c|c|c|c|c|c|c|c|}
\hline \multirow{2}{*}{ Drug } & \multirow{2}{*}{ Conc. Range $(\mu \mathrm{g} / \mathrm{ml})$} & \multirow{2}{*}{ Method } & \multicolumn{2}{|c|}{ Divisor } & \multirow{2}{*}{$\lambda(\mathbf{n m})$} & \multicolumn{3}{|c|}{ Linear Regression } \\
\hline & & & Name & Conc. $(\mu \mathrm{g} / \mathrm{ml})$ & & $\mathbf{a}$ & b & $\mathbf{r}$ \\
\hline ASP & $1.6-8.0$ & ${ }^{1} \mathrm{DD}$ & SAL & $\begin{array}{l}0.13 \\
0.32 \\
0.45\end{array}$ & 313 & $\begin{array}{l}0.02403 \\
0.02413 \\
0.01476\end{array}$ & $\begin{array}{l}0.6295 \\
0.5685 \\
0.4851\end{array}$ & $\begin{array}{l}0.9974 \\
0.9973 \\
0.9969\end{array}$ \\
\hline DIP & $2.4-9.6$ & ${ }^{1} \mathrm{DD}$ & SAL & $\begin{array}{l}0.13 \\
0.32 \\
0.45\end{array}$ & 484 & $\begin{array}{c}-0.3283 \\
0.2254 \\
-0.02508\end{array}$ & $\begin{array}{l}6.823 \\
4.145 \\
2.261\end{array}$ & $\begin{array}{l}0.9972 \\
0.9983 \\
0.9971\end{array}$ \\
\hline DIP & $2.4-9.6$ & ${ }^{1} \mathrm{DD}$ & ASP & $\begin{array}{l}1.6 \\
3.2 \\
4.8\end{array}$ & 516 & $\begin{array}{l}-0.1773 \\
-0.6486 \\
-0.6864\end{array}$ & $\begin{array}{l}35.22 \\
29.80 \\
12.98\end{array}$ & $\begin{array}{l}0.9995 \\
0.9983 \\
0.9998\end{array}$ \\
\hline SAL & $0.13-0.77$ & ${ }^{2} \mathrm{DD}$ & ASP & $\begin{array}{l}1.6 \\
3.2 \\
4.8\end{array}$ & 398 & $\begin{array}{c}-4.629 \times 10^{-5} \\
-0.3248 \times 10^{-5} \\
0.3187 \times 10^{-5}\end{array}$ & $\begin{array}{l}0.09738 \\
0.05194 \\
0.03168\end{array}$ & $\begin{array}{l}0.9992 \\
0.9972 \\
0.9994\end{array}$ \\
\hline
\end{tabular}

a: Intercept.

b: Slope.

r: Coefficient of correlation.

Table 2. Validation Parameters of the Calibration Curves and Limits of Detection and Quantitation by the HPLC Method

\begin{tabular}{|c|c|c|c|c|c|c|c|}
\hline Compound & Conc. Range $(\mu \mathrm{g} / \mathrm{ml})$ & Regression Equation $\mathbf{y}=\mathbf{a x}+\mathbf{b}$ & $\mathbf{r}$ & $\mathbf{S}_{\mathbf{a}}$ & $\mathbf{S}_{\mathrm{b}}$ & LOD & LOQ \\
\hline ASP & $25-100$ & $0.0486 \mathrm{x}+8.7 \mathrm{x} 10^{-3}$ & 0.9995 & $7.246 \times 10^{-3}$ & $1.058 \times 10^{-4}$ & 0.026 & 0.074 \\
\hline DIP & $30-120$ & $0.0191 x+9.3 \times 10^{-4}$ & 0.9998 & $1.739 \times 10^{-3}$ & $2.041 \times 10^{-5}$ & 0.044 & 0.153 \\
\hline SAL & $10-60$ & $0.1398 \mathrm{x}+4.5 \mathrm{x} 10^{-3}$ & 0.9996 & $8.665 \times 10^{-3}$ & $2.518 \times 10^{-4}$ & 0.015 & 0.085 \\
\hline
\end{tabular}

LOD: Limit of detection.

LOQ: Limit of quantitation.

$\mathrm{S}_{\mathrm{a}}$ : Standard deviation of the intercept.

$\mathrm{S}_{\mathrm{b}}$ : Standard deviation of the slope. 
$A S P$ is a moisture sensitive drug, it decomposes upon exposure to moisture yielding salicylic (SAL) and acetic acids. So, the need to develop a method of analysis of this mixture in presence of SAL is of great importance.

\subsection{Spectrofluorimetric Method}

The emission spectra (Fig. 1) of the ternary mixture components (ASP,DIP and $S A L)$ are strongly overlapped.

Preliminary attempts to analyze this mixture using a derivative technique with zero-crossing point failed to determine ASP and SAL due to marked interference and strong overlapping from DIP spectrum (Fig. 2).

Therefore, a derivative ratio spectrofluorimetric method was established for determination of the ternary mixture components. In this respect, the excitation wavelength was determined by measuring the excitation spectrum for each drug such that the emission wavelength was $345 \mathrm{~nm}$. It was found that the excitation wavelengths were 270,285 , and $275 \mathrm{~nm}$ for $A S P, D I P$ and $S A L$, respectively. To determine the optimum excitation wavelength, emission of the three drugs were done at the three excitation wavelengths and it was found that the optimum one was $270 \mathrm{~nm}$.

The method involved the use of zero-crossing technique and the first and second derivative of the ratio of emission spectra $\left({ }^{1} D D\right.$ and $\left.{ }^{2} D D\right)$ to solve such ternary mixture.

It is important to mention here that the choice of the optimum parameters for the determination of the three components by the proposed method was done by carrying out trials to choose the divisor, based on finding zero-crossing points, the maximum wavelengths for measurements and the $\Delta \lambda$ for calculating the first and second derivatives.

Therefore, for the determination of $A S P$, the stored emission spectra of standard solutions of $A S P, D I P, S A L$ and solution of their mixtures were divided (amplitude by amplitude at appropriate wavelengths) by the emission spectrum of a standard solution of $0.32 \mu \mathrm{g} / \mathrm{ml} S A L$; then, the first derivative of the ratio spectra were calculated with $\Delta \lambda=1 \mathrm{~nm}$ (Fig. 3A). This figure showed that the first derivative of the ratio spectrum of the mixture consists only of $A S P$ and $D I P$, where the corresponding values of $S A L$ were equal to zero. From this figure, $A S P$ can be determined in this mixture by measuring the amplitudes at $313 \mathrm{~nm}$ (zero-crossing of $D I P$ ) where there is no contribution from DIP.

On the other hand, DIP can be assayed by measuring the amplitudes at $484 \mathrm{~nm}$, which corresponds to zero-crossing point of $A S P$.

For determination of $S A L$ in the mixture, a similar procedure was followed, where the emission spectra of the standard solutions and the mixture were divided by that of $1.6 \mu \mathrm{g} / \mathrm{ml}$ $A S P$, and the second derivative of the developed ratio spectra were calculated with $\Delta \lambda=1 \mathrm{~nm}$ (Fig. 3B). It was shown from the figure that the second derivative of the ratio spectrum of the mixture consists only of $S A L$ and $D I P$ as the corresponding values of $A S P$ are equal to zero. Applying the zero-crossing method, $S A L$ can be assayed by measuring the amplitude at $398 \mathrm{~nm}$ (zero-crossing point of $D I P$ ), and $D I P$ can be determined by measuring the amplitudes of the first derivative of the ratio spectra at $516 \mathrm{~nm}$ (zero-crossing of $S A L$ ).

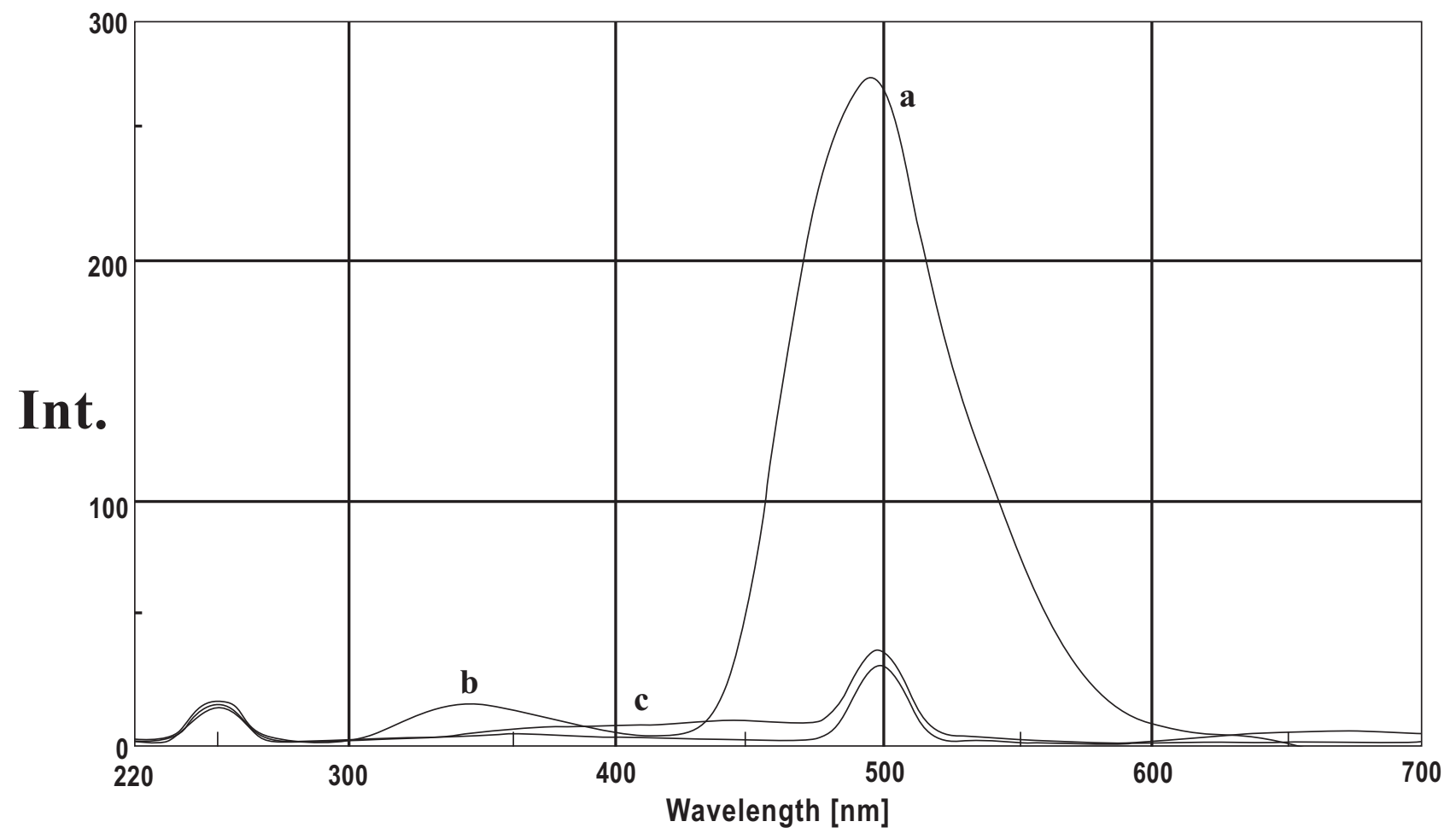

Fig. (1). Excitation-Emission spectra of (a) $0.24 \mathrm{mg} \% D I P$, (b) $0.16 \mathrm{mg} \% A S P$ and (c) $0.032 \mathrm{mg} \% S A L$. 

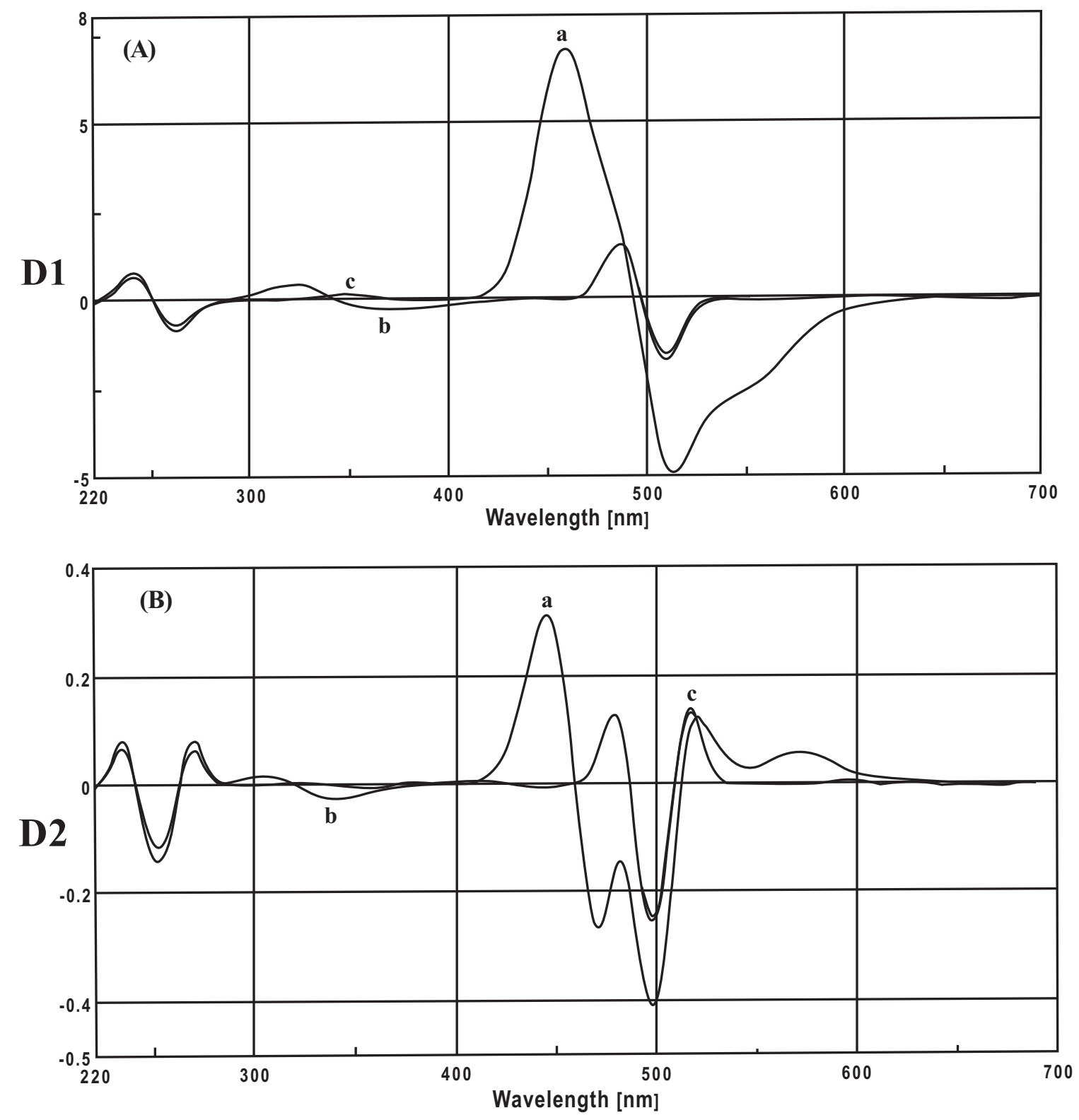

Fig. (2). (A) First and (B) second spectrofluorimetric derivative spectra of: (a) $0.24 \mathrm{mg} \%$ DIP, (b) $0.16 \mathrm{mg} \% A S P$ and (c) $0.032 \mathrm{mg} \% S A L$.

Therefore, $A S P$ and $D I P$ can be determined simultaneously using $S A L$ as divisor, while $D I P \& S A L$ can be determined simultaneously using $A S P$ as divisor. The final parameters for the assay of each component were summarized in Table $\mathbf{1}$.

The influence of $\Delta \lambda$ for obtaining the first derivative of the ratio spectra was tested to obtain the optimum wavelength interval; $\Delta \lambda=1 \mathrm{~nm}$ was considered as suitable.

\subsubsection{Effect of Divisor Concentration}

The effect of divisor concentration on the calibration graphs was studied. Thus, the emission spectra of different concentrations of $A S P, D I P$ and $S A L$ were recorded, and the amplitudes of each set of these solutions were divided by the amplitudes of the corresponding divisor (Table 1). The resul- tant ratio spectra were then differentiated with respect to wavelength using $\Delta \lambda=1 \mathrm{~nm}$. The derivative values of each component were measured at the specified wavelengths, and plotted against their concentrations. The data obtained from the statistical analysis of these graphs using the least squares method were shown in Table 1. The results obtained from this study using three different levels of divisor concentration (Table 1) indicate that the divisor concentration has no effect on the assay. If the concentration of the divisor is increased or decreased, the resulting first and second derivative values of the ratio spectra are proportionately decreased or increased, although the maxima and minima remain at the same wavelengths. This means that the magnitude of the divisor concentration does not affect each of the assay parameters, the position of the selected wavelengths and the linearity of the curve. It affects only the slope of the curve. 

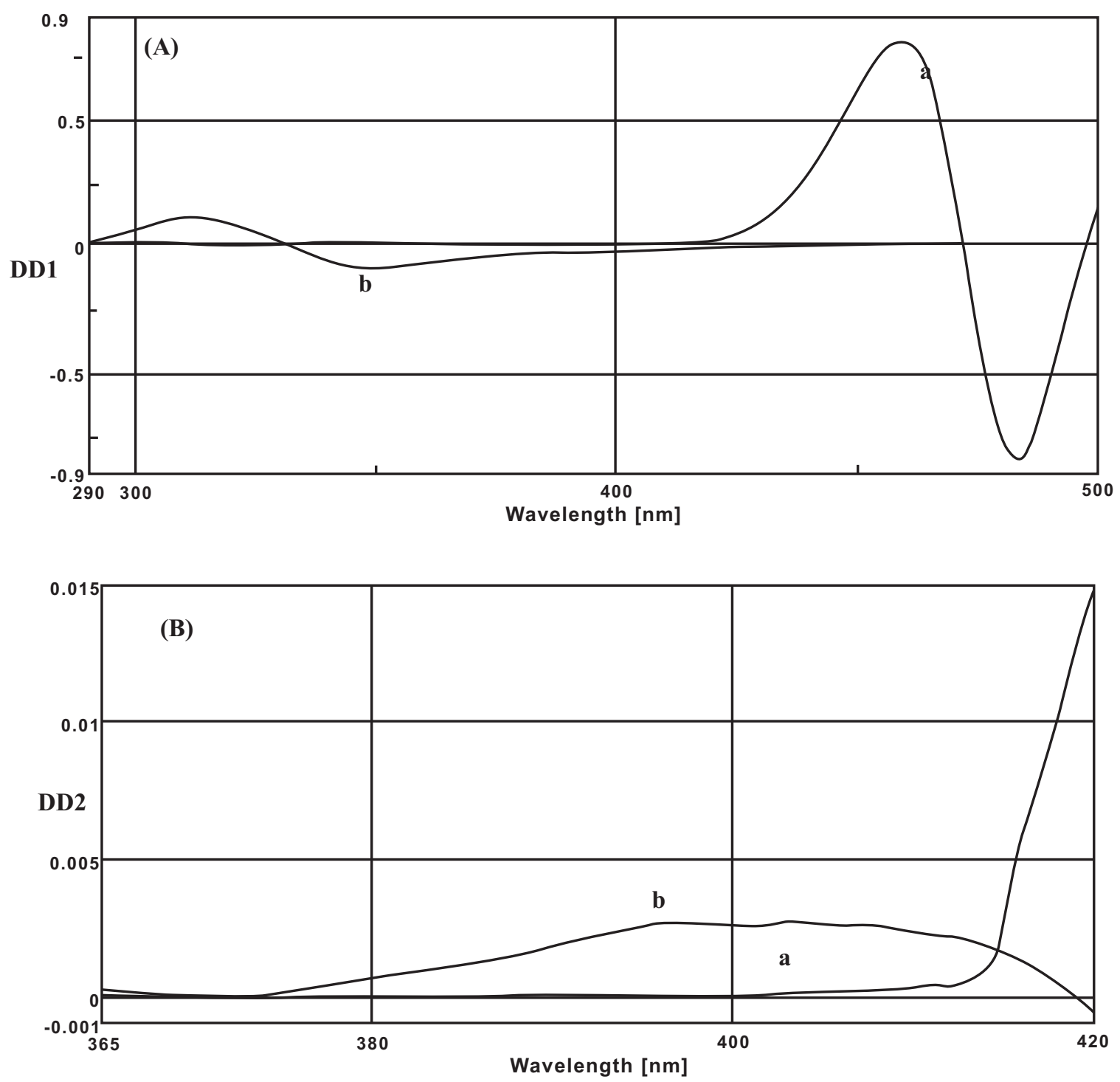

Fig. (3). (A) First derivative ratio spectra of: (a) $0.24 \mathrm{mg} \% D I P$ and (b) $0.16 \mathrm{mg} \% A S P$ using $0.032 \mathrm{mg} \% S A L$ as a divisor, (B) second derivative ratio spectra of: (a) $0.24 \mathrm{mg} \% D I P$ and (b) $0.032 \mathrm{mg} \% S A L$ using $0.16 \mathrm{mg} \% A S P$ as a divisor.

\subsubsection{Linearity}

The linearity of the proposed method was investigated for each drug by analyzing a series of different concentrations of each of $A S P, D I P$ and $S A L$, within the concentration range shown in Table 3 . The assay was carried out according to the above mentioned conditions. The derivative ratio values of each drug were measured at the specified wavelengths (Table 3) and plotted against concentration. A straight line was obtained in each case. The statistical analysis of these graphs showed good linearity and compliance with Beer's law, as seen from the values of correlation coefficients and small values of intercept (Tables $\mathbf{1}$ and 3). Moreover, synthetic mixtures consisting of different concentrations of each component, in the absence and presence of certain concentrations of the other components, were prepared and analyzed under the stated experimental conditions (Table 3). The graphs obtained by plotting the derivative ratio values of each drug in the mixture at the specified wavelengths versus concentration in the range stated in Table $\mathbf{3}$, exhibited linear relationships. A critical evaluation of the proposed method was performed by the statistical analysis of the data, where slopes, intercepts and correlation coefficients were shown in Table 3. High values of correlation coefficients and small values of intercepts validated the linearity of the calibration graphs and the obedience to Beer's law. The slope was independent on the concentration of the other component in the mixture (Table 3).

\subsubsection{Precision}

To test the repeatability of the proposed method, separate six determinations at different concentration levels were carried out for each drug alone and in the presence of other components. The results obtained showed that the relative standard deviation was less than $2 \%$ which indicated the high precision of the assay Table 4. 
Table 3. Assay Parameters for Analysis of $A S P, D I P$ and $S A L$ in Synthetic Mixtures by the Spectrofluorimetric Method

\begin{tabular}{|c|c|c|c|c|c|c|c|c|c|c|}
\hline \multicolumn{3}{|c|}{ Sample Conc. $(\mu \mathrm{g} / \mathrm{ml})$} & \multicolumn{2}{|c|}{ Divisor } & \multirow[b]{2}{*}{ Method } & \multirow[b]{2}{*}{$\lambda(\mathrm{nm})$} & \multicolumn{3}{|c|}{ Linear Regression } & \multirow[b]{2}{*}{ CV\% } \\
\hline ASP & DIP & SAL & Name & $\begin{array}{l}\text { Conc. } \\
(\mu \mathrm{g} / \mathrm{ml})\end{array}$ & & & $\mathbf{a}$ & b & $\mathbf{r}$ & \\
\hline $1.6-8.0$ & - & - & \multirow{2}{*}{ SAL } & \multirow{2}{*}{0.32} & \multirow{2}{*}{${ }^{1} \mathrm{DD}$} & \multirow{2}{*}{313} & 0.02413 & 0.6295 & 0.9973 & 0.6718 \\
\hline $1.6-8.0$ & 2.4 & 0.32 & & & & & 0.02016 & 0.6323 & 0.9975 & 0.8440 \\
\hline- & $2.4-9.6$ & - & \multirow{2}{*}{ SAL } & \multirow{2}{*}{0.32} & \multirow{2}{*}{${ }^{1} \mathrm{DD}$} & \multirow{2}{*}{484} & 0.2254 & 4.145 & 0.9983 & 1.312 \\
\hline 1.6 & $2.4-9.6$ & 0.32 & & & & & 0.2445 & 4.064 & 0.9955 & 0.6810 \\
\hline- & 2.4-9.6 & - & \multirow{2}{*}{ ASP } & \multirow{2}{*}{4.8} & \multirow{2}{*}{${ }^{1} \mathrm{DD}$} & \multirow{2}{*}{516} & -0.6864 & 29.79 & 0.9998 & 1.047 \\
\hline 1.6 & $2.4-9.6$ & 0.32 & & & & & -0.4202 & 29.06 & 0.9987 & 0.8690 \\
\hline- & - & $0.13-0.77$ & \multirow{2}{*}{ ASP } & \multirow{2}{*}{4.8} & \multirow{2}{*}{${ }^{2} \mathrm{DD}$} & \multirow{2}{*}{398} & $3.187 \times 10^{-6}$ & 0.05194 & 0.9994 & 0.5622 \\
\hline 1.6 & 2.4 & $0.13-0.77$ & & & & & $1.265 \times 10^{-5}$ & 0.05040 & 0.9999 & 0.6070 \\
\hline
\end{tabular}

a: Intercept.

b: Slope.

r: Coefficient of correlation

Table 4. Assay Results of Standard Solutions of $A S P, D I P$ and $S A L$ by the Spectrofluorimetric Method

\begin{tabular}{|c|c|c|c|c|c|}
\hline ASP Conc. Range $(\mu \mathrm{g} / \mathrm{ml})$ & \% Recovery & DIP Conc. Range $(\mu \mathrm{g} / \mathrm{ml})$ & \% Recovery & SAL Conc. Range $(\mu \mathrm{g} / \mathrm{ml})$ & \% Recovery \\
\hline 1.6 & 99.52 & 2.4 & 101.7 & 0.13 & 98.88 \\
\hline 4.8 & 99.78 & 7.2 & 99.87 & 0.45 & 98.13 \\
\hline 6.4 & 100.1 & 8.4 & 98.27 & 0.64 & 98.77 \\
\hline S.D. & 0.6675 & S.D. & 1.3074 & S.D. & 0.5562 \\
\hline CV\% & 0.6718 & CV\% & 1.3121 & CV\% & 0.5622 \\
\hline
\end{tabular}

S.D.: Standard deviation.

$\mathrm{CV} \%$ : Coefficient of variation.

\subsubsection{Selectivity}

Synthetic mixtures consisting of different concentrations of each component, in the presence of constant concentrations of the other components, were prepared and analyzed under the stated experimental conditions. Statistical analysis of the data revealed that the slope of the calibration graph was independent on the concentration of the other components in the mixture (Table 3). Thus, the derivative ratios are only dependent on the concentration of the drug at the specified wavelengths, which proves the high selectivity of the proposed method. Also, the values of the standard deviation did not vary markedly between the assay of the drug alone and its corresponding mixtures (Table 3 ).

\subsubsection{Accuracy}

The accuracy of the proposed method was tested by calculating the recoveries of each drug spiked either with the other components in the mixture or with common tablet excipients. Each drug was tested at five levels below and above the ratio labeled in the pharmaceutical tablets. Good recoveries were obtained as shown in Table $\mathbf{5}$, indicating no inter- ference from excipients or other components in dosage forms.

Table 5. Assay Results for the Determination of $A S P$, DIP and $S A L$ in Synthetic Mixtures by the Spectrofluorimetric Method

\begin{tabular}{|c|c|c|c|c|}
\hline \multicolumn{2}{|c|}{ Drug Conc. $(\boldsymbol{\mu g} / \mathrm{ml})$} & \multirow{2}{*}{$\%$ Recovery Mean \pm S.D. } & \multirow{2}{*}{ CV\% } \\
\hline ASP & DIP & SAL & & \\
\hline \hline $1.6-8.0$ & 2.4 & 0.32 & $98.87 \pm 0.835$ & 0.844 \\
\hline 1.6 & $2.4-9.6$ & 0.32 & $99.64 \pm 1.307$ & 1.312 \\
\hline 1.6 & 2.4 & $0.13-0.77$ & $99.46 \pm 0.604$ & 0.607 \\
\hline
\end{tabular}

CV\%: Coefficient of variation.

\subsubsection{Detection and Quantitation Limits}

According to ICH recommendations [12] the approach based on the standard deviation of the response and the slope was used for determining the detection and quantitation lim- 
its. In this respect, six separate determinations of the solvent, being $1 \%$ glacial acetic acid in chloroform in this case, were held spectrofluorimetrically and in each case the first or second derivative was measured at the specified wavelengths (Table 6). The calculated LOD and LOQ are shown in Table 6.

Table 6. Detection and Quantitation Limits for the Spectrofluorimetric Determination of ASP, DIP and SAL in Dosage Forms

\begin{tabular}{|c|c|c|c|c|}
\hline \multirow{2}{*}{ Drug } & \multirow{2}{*}{ Method } & \multirow{2}{*}{ S.D. } & \multicolumn{2}{|c|}{ Conc. $(\boldsymbol{\mu g} / \mathbf{m l})$} \\
\cline { 4 - 5 } & & & LOD & LOQ \\
\hline \hline ASP & D1 $(313 \mathrm{~nm})$ & 0.0042 & 0.21 & 0.97 \\
\hline DIP & D1 $(484 \mathrm{~nm})$ & 0.0199 & 0.37 & 1.28 \\
\hline SAL & D2 $(398 \mathrm{~nm})$ & 0.0038 & 0.25 & 0.36 \\
\hline
\end{tabular}

S.D.: Standard deviation.

LOD: Limit of detection.

LOQ: Limit of quantitation.

\subsubsection{Dosage form Analysis}

The developed method was applied to determine ASP and $D I P$ in dosage forms. The results obtained were precise and accurate, and showed high selectivity and repeatability (Table 7).

\subsection{HPLC Method}

A new RP-HPLC method for simultaneous determination of $A S P$ and DIP in presence of $S A L$ has been developed and evaluated. The method was tested for selectivity, linearity, sensitivity, accuracy and precision.

Optimal chromatographic parameters were achieved with the mobile phase consisting of water-acetonitrile-orthophosphoric acid (65:35:2 v/v/v), on an Adsorbosil $\mathrm{C}_{8}$ column (250mm x $4.6 \mathrm{~mm}$, particle size $10 \mu \mathrm{m})$ at ambient temperature. The pump operated in an isocratic mode at a flow rate of $1.5 \mathrm{ml} / \mathrm{min}$. The UV-detection was performed at $250 \mathrm{~nm}$. Injections were carried out using a $20 \mu \mathrm{L}$ loop. Representa-

Table 7. Assay Results for Determination of $A S P$ and $D I P$ in Dosage forms by the Spectrofluorimetric and HPLC Methods

\begin{tabular}{|c|c|c|c|c|c|c|c|c|}
\hline \multirow{2}{*}{ Drug } & \multicolumn{2}{|c|}{ Divisor } & \multirow{2}{*}{ Method } & \multirow{2}{*}{$\lambda(\mathbf{n m})$} & \multicolumn{2}{|l|}{ Spectrofluorimetry } & \multicolumn{2}{|l|}{ HPLC } \\
\hline & Name & Conc. $(\mu \mathrm{g} / \mathrm{ml})$ & & & $\%$ Recovery Mean \pm S.D. & $\mathrm{CV} \%$ & $\%$ Recovery Mean \pm S.D. & $\mathrm{CV} \%$ \\
\hline ASP & SAL & 0.32 & ${ }^{1} \mathrm{DD}$ & 313 & $99.77 \pm 0.863$ & 0.865 & $99.96 \pm 1.1472$ & 1.1476 \\
\hline \multicolumn{9}{|c|}{ ASP: F-test $\left(F_{\text {theoretical }}\right)=2.5886(6.59)$ Student's t-test $\left(t_{\text {theoretical }}\right) t=0.3538(2.365)$} \\
\hline DIP & SAL & 0.32 & ${ }^{1} \mathrm{DD}$ & 484 & $100.34 \pm 1.434$ & 1.429 & $100.92 \pm 0.9592$ & 0.9504 \\
\hline \multicolumn{9}{|c|}{ DIP: $F$-test $\left(F_{\text {theoretical }}\right)=1.4852(9.12)$ Student's t-test $\left(t_{\text {theoretical }}\right)=0.6069(2.365)$} \\
\hline DIP & ASP & 4.8 & ${ }^{1} \mathrm{DD}$ & 516 & $99.56 \pm 1.065$ & 1.070 & $99.61 \pm 0.8564$ & 0.8597 \\
\hline SAL & ASP & 4.8 & ${ }^{2} \mathrm{DD}$ & 398 & - & - & - & - \\
\hline
\end{tabular}

S.D.: Standard deviation.

$\mathrm{CV} \%$ : Coefficient of variation.

$\mathrm{F}_{\text {theoretical }}$ and $\mathrm{t}_{\text {theoretical }}$ were determined at $95 \%$ confidence level.

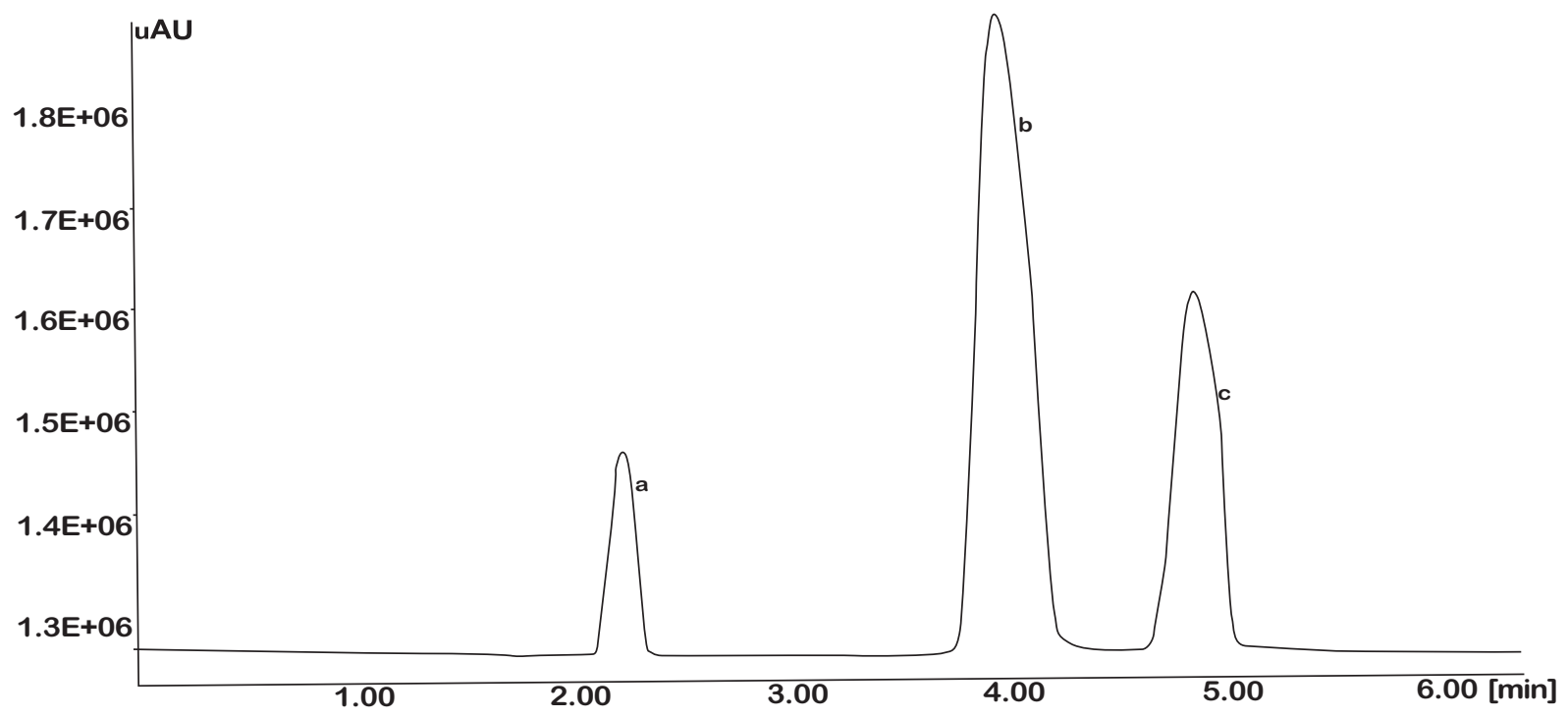

Fig. (4). Liquid chromatographic separation of the mixture of (a) $150 \mu \mathrm{g} \mathrm{ml}^{-1} D I P$, (b) $100 \mu \mathrm{g} \mathrm{m}{ }^{-1} A S P$, and (c) $40 \mu \mathrm{g} \mathrm{ml}{ }^{-1} S A L$ using the chromatographic conditions described in the text. 
tive chromatogram obtained from working solution mixture of $A S P$ and $D I P$ in presence of $S A L$ as impurity is shown in Fig. (4).

Under described conditions, RP-HPLC procedure was performed. Optimal chromatographic parameters such as retention time $\left(t_{R}\right)$, retention factor $\left(K^{\prime}=t_{R}-t_{0} / t_{0}\right)$, symmetry factor $\left(\mathrm{As}=\mathrm{W}_{0.05} / 2 \mathrm{~d}\right)$, resolution $\left(\mathrm{Rs}=1.18^{*}\left(\mathrm{t}_{\mathrm{R} 2}-\mathrm{t}_{\mathrm{R} 1} /\right.\right.$ $\left.\mathrm{W}_{\mathrm{h} 1}+\mathrm{W}_{\mathrm{h} 2}\right)$, separation factor $\left(\alpha=\mathrm{K}_{2}{ }^{\prime} / \mathrm{K}_{1}{ }^{\prime}\right)$, plate number $\left(\mathrm{N}=5.54 *\left(\mathrm{t}_{\mathrm{R}} / \mathrm{W}_{\mathrm{h}}\right)^{2}\right)$ and height equivalent to one theoretical plate $(\mathrm{HETP}=\mathrm{L} / \mathrm{N})$ are listed in Table $\mathbf{8}$.

Tests for selectivity, sensitivity, linearity, accuracy and precision of the method afforded satisfactory results. Qualitative comparison of the chromatograms obtained from standard and sample solutions showed that the selectivity of the HPLC method was good.

The calibration curves were evaluated by their correlation coefficients. Linearity for $A S P, D I P$ and $S A L$ was assessed within the concentration range stated in Table $\mathbf{2}$.

Both limit of detection (LOD) and limit of quantitation (LOQ) were calculated according to the equation: $\mathrm{LOD}=$ $\mathrm{B}+3 \mathrm{~s}$ and $\mathrm{LOQ}=\mathrm{B}+10 \mathrm{~s}$, where $\mathrm{s}$ and $\mathrm{B}$ are the standard deviation and the mean of 10 independent sample blank values. The values of LOD and LOQ are listed in Table 2.

The precision of the chromatographic procedure was investigated for three concentrations from the calibration plots of each of $A S P, D I P$ and $S A L$. Analyzing seven solutions for the three chosen concentrations from the calibration plots of each substance assessed precision of the chromatographic procedure. From the results listed in Table 9, it can be seen that the relative standard deviation values $(\mathrm{RSD}<2 \%)$ and repeatability were satisfactory [13].

Accuracy for the assay of $A S P, D I P$ and $S A L$ was also investigated. The closeness of the measured value to the true value for the sample (accuracy) was assessed by analyzing a sample of known concentration and comparing the measured value to the true value [14]. The accuracy results presented in Table 9, show satisfactory values of mean recovery per concentration (98.0-102.0\%) for $A S P, D I P$ and $A S P$ degradation product and satisfactory accuracy of the system [13].

Synthetic mixtures containing different concentration ratios of the three components (Table 10) were prepared and analyzed by the proposed HPLC method. The \% recoveries obtained for each component proved the high accuracy of the method (Table 10).

The proposed HPLC method was applied for the determination of $A S P$ and DIP in dosage forms. The results obtained showed high precision and accuracy of the method (Table 7).

Moreover, the results obtained by HPLC method were comparable to those obtained by spectrofluorimetric method (Table 7), as seen from the $\mathrm{F}$ and t-tests results.

Table 8. Statistical Analysis of the Parameters Required for System Suitability Test of HPLC Method

\begin{tabular}{|c|c|c|c|c|}
\hline As (symmetry factor) & 1.17 & 1.12 & 1.05 & $A s=1$ for a typical symmetric peak \\
\hline$\alpha$ (relative retention) & \multicolumn{2}{|c|}{2.212} & 1.288 & $>1$ \\
\hline $\mathrm{N}$ (column efficiency) & 1009.7 & 1958.1 & 2035.2 & Increases with efficiency of the separation \\
\hline HETP & 0.0198 & 0.0102 & 0.0098 & The smaller the value, the higher the column efficiency \\
\hline Retention time (min) & 2.2 & 3.8 & 4.6 & - \\
\hline
\end{tabular}

Table 9. Accuracy and Precision of the HPLC Assay Method Expressed as Recovery Values (\%) and RSD\%

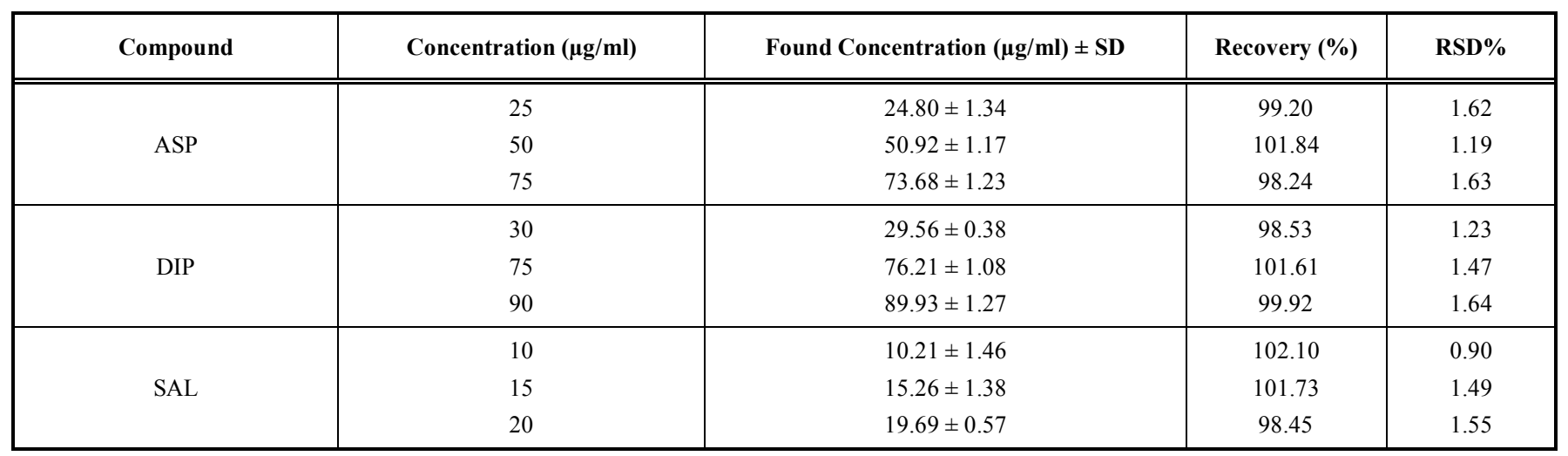


Table 10. Determination of DIP, ASP and $S A L$ in Laboratory Prepared Mixtures by the Proposed HPLC Method

\begin{tabular}{|c|c|c|c|c|c|}
\hline \multicolumn{3}{|c|}{ Concentration $(\mu \mathrm{g} / \mathrm{ml})$} & \multicolumn{3}{|c|}{ \% Recovery } \\
\hline$D I P$ & $A S P$ & $S A L$ & $D I P$ & $A S P$ & $S A L$ \\
\hline 75 & 50 & 20 & 100.92 & 99.96 & 101.43 \\
\hline 150 & 100 & 40 & 99.34 & 98.99 & 100.79 \\
\hline 300 & 100 & 40 & 98.68 & 101.24 & 98.78 \\
\hline 150 & 150 & 40 & 100.58 & 98.42 & 99.53 \\
\hline 150 & 200 & 40 & 100.39 & 99.67 & 99.26 \\
\hline 150 & 100 & 10 & 99.96 & 99.83 & 100.95 \\
\hline \multicolumn{3}{|c|}{ Mean Rec. \pm RSD \% } & $99.97 \pm 0.8461$ & $99.68 \pm 0.9621$ & $100.12 \pm 1.0699$ \\
\hline
\end{tabular}

\section{CONCLUSION}

The proposed methods provide accurate, simple, rapid and reproducible quantitative analysis of $A S P, D I P$ and $S A L$ (as degradation product in dosage forms). These methods can be used for monitoring the stability of $A S P$ and $D I P$ in pharmaceutical dosage forms, as well. The run time of $6 \mathrm{~min}$ and flow rate of $1.5 \mathrm{ml} / \mathrm{min}$ allows the analysis of a large number of samples. The methods are efficient and sensitive means to determine $A S P$ and $D I P$, in presence of $A S P$ degradation product with no interference of excipients present in the pharmaceutical formulations demonstrating a high selectivity of the procedure. The methods can be successfully used in the quality control, as purity and stability testing.

\section{ACKNOWLEDGEMENT}

This work was supported by Beirut Arab University Quality Control Research Laboratory.

\section{REFERENCES}

[1] Hardman J, Goodman Gilman A, Limbird L. Goodman \& Gilman's The Pharmacological Basis of Therapeutics. The Mc Graw-Hill Companies: New York; 2001.

[2] ICH, Stability Testing of New Drug Substances and Products, International Conference on Harmonization, Geneva, 1993.

[3] Umapathi P, Parimoo P, Thomas SK, Agarwal V. Spectrofluorometric estimation of aspirin and dipyridamole in pure admixtures and in dosage forms. J Pharm Biomed Anal 1997; 15: 1703-8.

[4] El Yazbi FA, Abdine HH, Shaalan RA, Korany EA. Spectrophotometric determination of ternary mixtures by the derivative ratio- spectrum-zero crossing method. Spectrosc Lett 1998; 31(7): 14031414.

[5] 'Haver TCO, Green GL. Derivative spectrophotometry, low and higher order. Anal Chem 1976; 48: 312.

[6] El Yazbi FA, Korany MA, Bedair M. Application of derivativedifferential spectrophotometry for the determination of Oxazepam or Phenobarbitone in the presence of dipyridamole. J Pharm Belg 1985; 40(4): 244.

[7] Salinas F, Berzas Nevado JJ, Espinosa Mansilla A. A new spectrophotometric method for quantitative multicomponent analysis resolution of mixtures of Salicylic and Salicyluric acid. Talanta 1990; 37: 347 .

[8] El Yazbi FA, Kovar KA. A computerized spectrophotometric method for the determination of Atenolol and Nifedipine in presence of degradation products of Nifedipine. Sci Pharm 1998; 66: 325-33.

[9] El-Yazbi FA, Hammud HH, Assi SA. New spectrofluorometric application for the determination of ternary mixtures of drugs. Anal Chim Acta 2006; 580: 39-46.

[10] El-Yazbi FA, Hammud HH, Assi SA. Derivative-ratio spectrophotometric method for the determination of ternary mixture of aspirin, paracetamol and salicylic acid. Spectrochim Acta Part A Mol Biomol Spectrosc 2007; 68A: 275-278.

[11] El Yazbi FA, Hammud HH, Sonji GM. Determination of Telmisartan and Hydrochlorothiazide in binary mixture. Ultra Sci 2007 19(1): 93-104

[12] The European Agency for the Evaluation of Medical Products, ICH Topic Q 2B Note for Guidance on Validation of Analytical Procedures: methodology CPMP/ICH/281/95; 1996.

[13] Ahuja S, Scypinski S. Handbook of modern Pharmaceutical Analysis. Academic Press: San Diego; 2001.

[14] Green JM. A Practical Guide to Analytical Method Validation. Anal. Chem. News \& Features 1996; 68: 305A. 